\title{
An Investigation into the Effects of Risks and Risk Management of Bioenergy Projects
}

\author{
Aminu Bature ${ }^{1 *}$, Lynsey Melville ${ }^{1}$, Khondokar Mizanur Rahman ${ }^{1}$, Jahangir Akhtar ${ }^{1}$, \\ and Poonam Aulak ${ }^{1}$
}

${ }^{1}$ School of Engineering and the Built Environment, Birmingham City University, United Kingdom

\begin{abstract}
Risk is an important component in project management and plays a key role in securing project finance in renewable energy sector. As the amount of companies making investment in renewables grow, so do the inherent risks in the different stages of the projects. This study seeks to obtain information, which will help examine the risks associated with bioenergy projects and the methods used to identify, manage and reduce them. The study is conducted in the form of a survey with data being gathered using questionnaires. The results of this study shows that although when taken as a whole, policy and regulatory risk is the most significant risk associated with renewable energy projects, financial and environmental risks are the most important risks related to bioenergy projects. These suggest that financing, which is one of the key elements in maintaining, building and operating bioenergy plants faces substantial obstacles in managing it risks. Moreover, the study shows that insurance coverage and company-based risk management functions are the most important risk management tools for managing financial and environmental risks respectively. It is recommended that governments should strive to include bioenergy stakeholders in their policy development in order to integrate industry's perspective into the process.
\end{abstract}

Keywords: Bio-energy; Renewable Energy; Project Management; Risks, Risk Management

\section{Introduction}

According to the United Nations Environmental Programme (UNEP) and Bloomberg New Energy Finance (BNEF), the global investment in renewable energy was more than twice that of coal and gas-powered generation capacity in 2015 [1]. The amount invested rose to $\$ 285.9$ billion, some 5\% more than 2011's record of $\$ 278.5$ billion. The use of bio-energy sources including biomass, biofuels and bio-power, have particularly increased by a factor of five from 2001 to 2011 due to efforts to reduce the environmental externalities of fossil fuels [2], policy incentives through support schemes, and the growing emphasis on energy security. These however, raises the investment risks in renewable energy projects, and the availability of risk management resources such as risk expertise, insurance cover and industry data to manage the risks remains limited. Thus, potentially restricting cash flows, which

\footnotetext{
* Corresponding Author: Aminu.Bature@mail.bcu.ac.uk
} 
limits the industry's access to development capital. Although there has been an increasing interest in the literature on bio-energy technology for energy related greenhouse gas (GHG) emission mitigation $[3 ; 4 ; 5]$, there is comparatively little discussion about the risks inherent in bioenergy projects and the approaches taken to manage them $[6 ; 7]$.

This study seeks to obtain data that will help to examine the risks associated with bioenergy projects and the methods used to manage and reduce them. The study is conducted in the form of a survey (of over 50 renewable energy, and project and risk management experts), with data being gathered via questionnaires. The researchers also adopted the literature review approach to identify the significant risks commonly associated with bioenergy projects. The study offers some important insight into the most important risk(s) facing the bioenergy industry, the risk management challenges in the renewable energy sector, and the most common risk identification and transfer mechanism(s) used by experts in the industry.

The research shows that despite $59.65 \%$ of the respondents indicated that risk is "clearly defined and well communicated" in their organization, $40 \%$ of them also say that there is no standard risk management framework in their organization to implement risk management systematically and effectively. These suggest that the renewable energy sector faces obstacles in implementing risk management strategies. Moreover, financial risk is the most significant risk associated with bioenergy energy projects (flagged by $20.79 \%$.), followed by environmental risks (flagged by $19.80 \%$ ), operational (flagged by $16.83 \%$ ) and political and regulatory risks (flagged by 12.87 ). However, $43.40 \%$ of the survey respondents say that political and regulatory risks are the most significant risks associated with renewable energy projects. These indicate that although overall politicy and regulatory risk(s) are considered high profile, they may not be the main risk factors in the bioenergy industry. Yet, consistency in regulation and policy may play an important role in how companies investing in the bioenergy industry perceive risks.

\section{Materials and Methods}

In order to investigate renewable energy project risks and the effect of risk management on bioenergy projects, the researchers first derive from the literature the different categories of risks, which formed the bases for this study's survey. A comparative approach is used to discuss the survey results concerning the relevant risks, citing peer-reviewed academic journals, company reports, and books. Although there is no universal agreements regarding the optimal length of a survey, simple and straight to the point questionnaires generally attract high response rates than very long complex ones [8]. Moreover, meticulous attention was paid to make sure that each question is appropriate, relevant, intelligible, precise, and free from any kind of bias. The questionnaire was sent to 65 professionals in the fields of renewable energy, risk management, and project management. The target respondents were selected based on their occupational titles (such as renewable energy experts, project and risks managers). The response rate was $92 \%$ (60 response), with $76 \%$ of the respondents 
from the private sector, $15 \%$ from the public sector and the remaining $9 \%$ from other sectors.

Quantitative studies such as this are subjected to certain degree of indeterminacy $v i s-\grave{a}$-vis their intrinsic strength to depict the surveyed phenomenon. Moreover, the respondent's ontological view about reality fundamentally makes the results of the survey for this study essentially subjective. Another limitation is the survey questions, which are open to interpretation between the researcher's epistemological view of the "truth" and the "real truth". Another limiting factor of this study is the relatively small total amount of responses to the questionnaire. All these limitations need to be considered when examining the survey results of this study. However, notwithstanding it is to be believed that these findings can be beneficial to the body of knowledge of renewable energy particularly bioenergy, and to the project and risk management community.

\section{Results \& Discussion}

\subsection{Risk Definition and Risk Management Framework in the Renewable Energy Sector.}

Risk communication is an interactive process were stakeholders (such as institution, individuals and groups) exchange information and opinion about the nature of risks for risk management. It provides the means through which the public understand risk and defines the safety acceptance criteria [9]. According to the Institute of Risk Management (IRM), managing risk should be a continuous task that runs throughout an organization's strategy development and implementation [25]. Thus, understanding how well the risk is defined and communicated, and the standards or framework used is one of the key elements for understanding risk perception, risk management maturity and its impact in the renewable energy sector. When asked "How well is risk defined and/or communicated in your organization?" The majority of the respondents $(59.65 \%)$ replied that risk is well-defined and communicated between risk assessors and risk managers in their organization, which indicates that the potential for effective risk assessments in decision-making within these companies is high. Moreover, $15.79 \%$ of the respondent expressed their belief that each project manager in their organization defines his/her own risk(s). Another $12.28 \%$ of the respondents answered that, there is no clear definition of risk in their organization, as shown in Figure 1. These suggest that the transfer of risk related information and their management as well as the exchange of knowledge and values as a preventive activity to cope with hazard events and reduce impact on people, are well established within the renewable energy sector. However, this does not mean that there is always agreement among different stakeholders. 


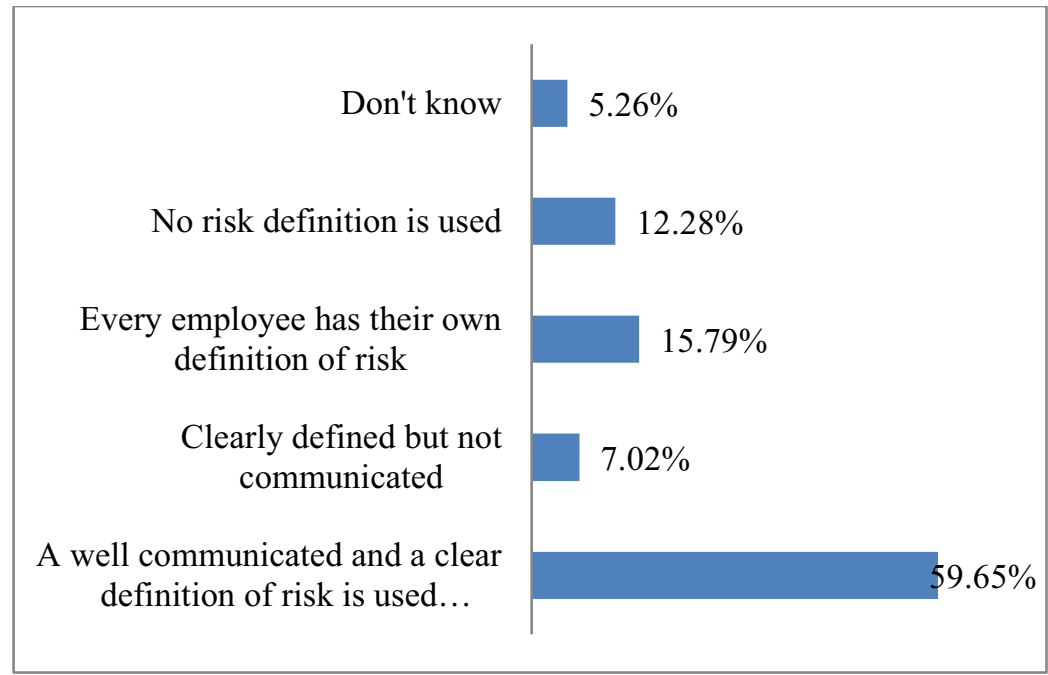

Figure 1. Risk definition and communication in renewable energy companies

Despite the unanimity of the respondents (59.65\%) in this research and the corroboration from the IRM survey in 2008, the mere definition of risk and/or communication is not enough. It is important not only to define and communicate the risks, but also to have a guiding framework that meets international standard, such as IRM [10] and ISO 31000:2009 standard [11] for effective implementation. When asked if there is any risk management framework in used in their organization? $40 \%$ of those who responded indicated that there is no standard risk management framework in their organization. However, $29.09 \%$ of the participants responded that a "company owned or IRM standard enterprise wide frameworks" is used in their organization. $18.18 \%$ of those who responded answered that every department in their organization have their own risk management framework, and a small number of the respondents $(12.73 \%)$ indicated that they do not know. These suggests that. Only a limited amount of renewable energy based companies have an established risk management framework. One respondent further states that "renewable energy project risks are often very complicated, confusing and lack consistency, therefore every department in his company has its own risk management framework. Therefore, most renewable energy consultants end up creating their own bespoke risks management methods and procedure". 


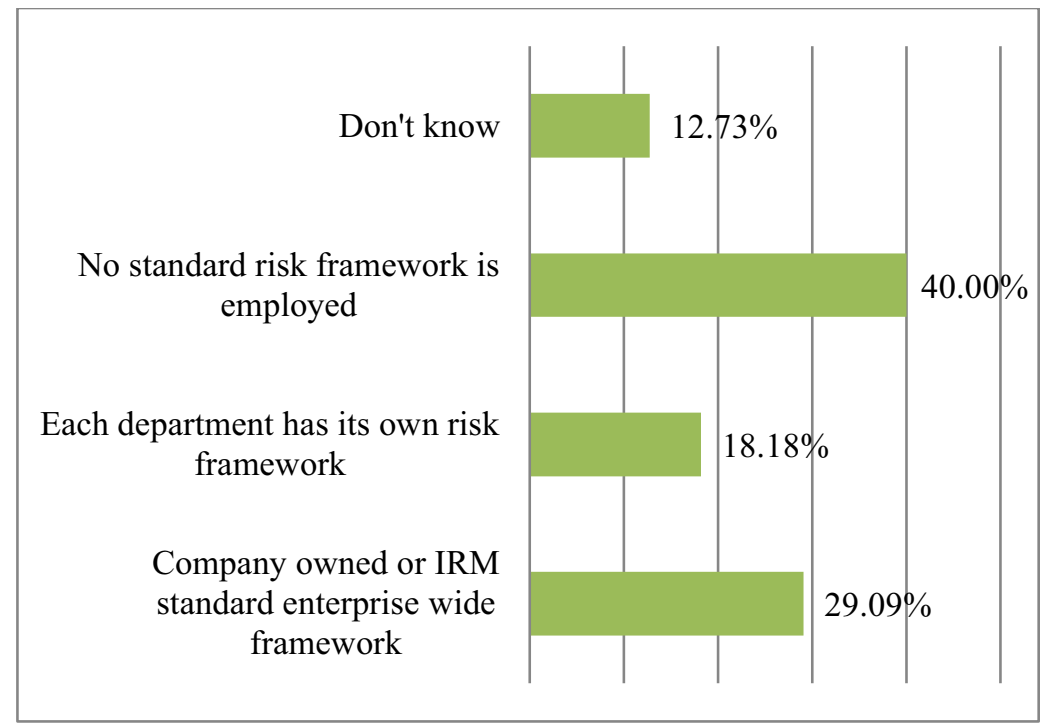

Figure 2. Risk Management Framework Adoption in the Renewable Energy Sector

This findings are inconsistent with those of previous work by the IRM, where more than half of their respondents $(66.3 \%)$ indicates that enterprise-wide framework (such as IRM standard) promoted by risk management team are widely used in their organizations such as Banking and Finance, Construction and Property, Food and Beverage, Technology, Media and Telecoms et cetra.

\subsection{Risk Identification, Assessment, and Response Action}

\subsubsection{Risk Identification}

This is the first step in the risk management cycle [12] that "stems from the decisionmaking conditions under which an investor is at the moment" [13]. Risk identification has been defined as the process of identifying all the potential risks associated with the objectives of the project [14]. In the Project Management Body of Knowledge (PMBOK), the PMI refers risk identification as "the process of determining which risks may affect the project and documenting their characteristics" [15]. According to a definition provided by the OGC's PRINCE2, risk identification is the step "that obtains information about the project in order to understand the specific objectives that are at risk and to formulate an appropriate risk management approach," the result of which can be found in the risk register of the project. This step in the risk management cycle also ensures the incorporation of lesson learnt from previous projects [16]. Moreover, subsequent stages of the risk management cycle such as risk assessment and control will not be possible to undertake when/if the risks have not been identified [17].

In the last decade, various studies have attempted to identify the different types of risk associated with renewable energy projects. For example, Xu et al. [39] identified 5 Critical Risk Factors (CRFs) by conducting content analysis on the risk events data of 14 waste-biomass incineration generation projects in China. These factors are 
enironmental risk, payment risk, insufficient waste supply, lack of support infrastructure, and disposal of non-lincensed waste. However, Langholtz et al. [2] in their review of the evidence from the 2012 U.S. drought, identifies six risks in the bioenergy industry due to extreme weather events including shortages of biomass feedstock, higher feedstock cost, product price volatility, seasonal scarcity, input price volatility, and the availability of water. Lee and Zhong [38] introduced the hybrid bond project financing instrument, illustrating how the bond could be used to finance and manage major project uncertainties including quantifiable: credit risks and market risks, and unquantifiable: operational risks, liquidity risks, and political risks. To investigate both the internal and external risk factors in the process of implementing a renewable energy project, Rolik [40], employed strategic management tools such as SWOT analysis and McKinsey matrix to classify the risks into: market risks, project risks and management risks. This view is supported by Jinrong and Enyi [41] who writes that risks inherent in energy projects include market risk, project quality risk, management risk, as well as technology risk, , political and legal risk, client risk, and financial risk. However, in another major study, GuerreroLiquet, et al. [43] investigated risk management tools in renewable energy facilities based on the Project Management Institute's (PMI) Project Management Body of Knowledge (PMBOK $®$ Guide), using information gathering (Delphi and Checklist) and diagram techniques (Fishbone Diagram (Ishikawa)) to categorized risks into technical risks, price risks and financial risks. A broader perspective has been adopted by Gatzert and Kosub [35] who conducted an in-depth literature review on the different type of risks associated with renewable energy projects and categorises them into strategic/business risks, transport/construction/completion risks, operation/maintenance risks, liability/legal risks, market/sales risks, counterparty risks, and political/policy/regulatory risks. Together these studies provide important insights into the different risks asscoiated with renewable energy projects. Moreover, the studies presented thus far provide evidence that suggests that by far the greatest risks associated with renewable energy projects including bioenergy projects may be categorised into technical risks, political and regulatory risks, financial risks, social risks, and environmental risks.

In this study, $94.8 \%$ of those who responded to this question were found to use some type of risk identification technique or approach to identify risks, with the exception of $5.2 \%$ as shown in Figure 2. This finding is in agreement with the Economist Intelligence Unit (2011) findings, which showed that (70\%) companies in the renewable energy sector are highly successful in identifying risk [18]. Moreover, this result corroborate the findings of previous work by the IRM on risk in other sectors. There are several techniques available to identify risks depending on the information and project players in hand. In the questionnaire developed for this study, the researchers present the participants with a set of risk identification techniques (see Figure 3 below) commonly found in the literature and used by practitioners $[19 ; 20$; $17]$. 


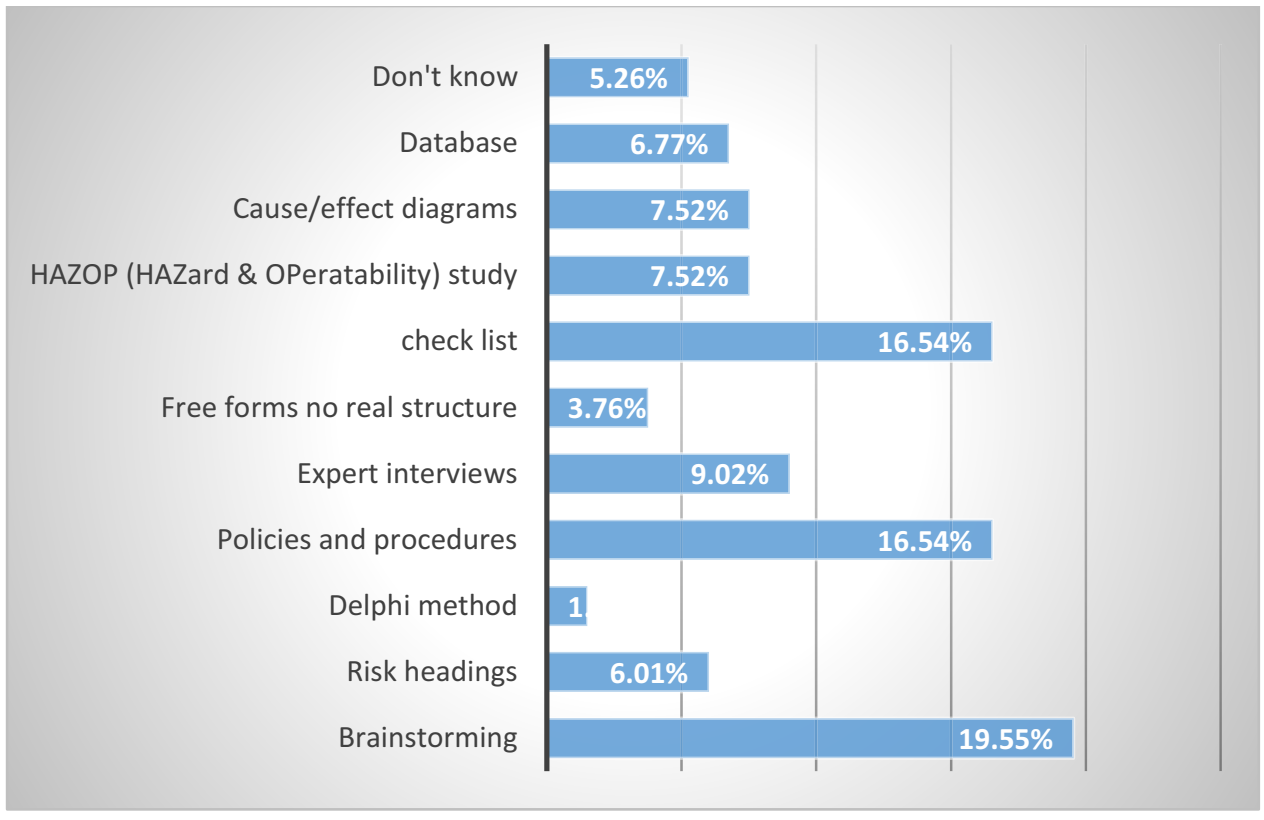

Figure 3. Risk Identification Techniques used in the Renewable Energy Sectors

\subsubsection{Risk Identification Techniques}

\subsection{Delphi Technique}

Dalkey and Helmer of RAND Corporation in California first developed this technique in the 1950s for gaining convergence of opinions concerning real-world knowledge solicited from subject matter experts within a given topic areas. Ever since, this method has been used by both practitioners and academics to collect data from respondents within their topic expertise [20]. It involves creating ways to gain agreement or disagreement (consensus) among experts in relation to a given problem by expressing their honest opinions about the risk posing threats to the project [22]. According to the IEA, the Delphi method also allow experts to revise their opinions and come up with new ideas [21]. Having discussed what the Delphi method is, this section of the questionnaire is designed to investigate common methods of identifying risks in renewable energy projects. Since more than one method can be used for large and complex projects with multiple departments, the respondents were offered a "select all that apply" response option. When asked which risk identification technique(s) do you used in your organization? Only $1.50 \%$ of the respondents choose this method.

\subsection{Brainstorming}

This "is a decision-making technique used to indicate verbal generation of ideas by a group" [23]. The technique was first introduced in the 1930s by Alex Osborne to generate and clarify ideas of potential risks by bringing together project stakeholders and subject matter experts under a facilitator [19; 21]. Osborn [45] defined brainstorming session as an approach that utilizes group of people to generate many ideas. According to Forbes et al. [17], brainstorming technique tend to be presented in a structured or unstructured (simple) approach. The objective of this risk 
identification technique is to collect as much ideas from a group of people as possible within a given period of time. The session begins by making sure that the participants understood very clearly the objectives of the gathering and that they are there to collaborate with each other. The goal of the session is to identify risks that are known unknowns as well as those that were unknown unknowns. From the survey, brainstorming is the most common method of identifying risk (19.55\%). This result is broadly consistent with earlier research [24; 25].

\subsection{Expert interviews}

This is considered the simplest form of risk identification were a series of questions are presented to industry experts to obtain their opinion in connection to potential risks [21]. This technique is widely used in different stages of the projects, and may be used to cover both internal and external risks [26]. It can be unstructured, semi structured, or structured [27]. Of the 54 participants who responded to this question, $9.02 \%$ reported to use expert interviews to identify risks. This is in contrast to earlier findings by Rostami [26], who found that expert judgement is the second most used risk identification technique in the construction phase of projects with a $71 \%$ usage rate.

\subsection{HAZOP (HAZard and OPerability analysis) and Other Risk Identification Techniques}

HAZOP is the process of identifying project hazards due to operational setbacks in the project activities [21]. Only $7.25 \%$ of those who responded indicated that HAZOP is used in their projects. According to the literature, other key techniques in identifying risks are: check-list, cause and effect diagram, data base (such as lesson learn logs and risks registers) and risk headings. Check list, and policies and procedures both $16.54 \%$. Some respondents indicated that cause and effect diagrams $(7.52 \%)$ is used in their organizations. A minority of participants $(6.77 \%)$ uses database or company documentation review method, which differ from Rostami [26] result were $75 \%$ of the respondents considered this technique as their most preferred tool for identifying risk. (6.01\%) uses risk headings to identify risk in their projects. Moreover, three participants offers other methods used in their organizations such as internally development ERM matrix, probability distributions, and successive principle by Steen Lichtenberg.

\subsubsection{Risk Analysis and Assessment}

The term risk analysis is open to a series of definitions. For example, Moddares, et al. [28], defines risk analysis as a method for identifying, characterizing, quantifying, and evaluating hazards. Martinez [29] described risk analysis as a proactive type of methodology for the identification of weaknesses and threats to organization's assets. A further definition is given by Galway [46] who describes risk analysis as the process of qualitatively and quantitatively assessing risk. In the field of renewable energy, Ferraris et al. [47] defines risk analysis as the process of scientifically characterizing "what is known and what is uncertain about the present and future 
performance of the system under examination". In this research, the term risk analysis will be used interchangeably with (or to include) risk assessment when referring to all measures taken to determine the likelihood of failure in meeting project objectives; to improve how decisions are made within the project, and; to help minimize the project exposure to risks $[28 ; 29 ; 30]$. Some of the methods used in risk analysis include the stochastic critical path method (CRM) for schedule risks, and the stochastic simulation of cost, both of which require Monte Carlo simulation and specification of uncertainty for the project time and cost. According to Razaque et al. [48], this stage in the risk management cycle helps reduce risk and anticipate the future repercussions of decision taken. Moreover, it involves the identification of the risk control mechanisms, and the resultant amount of controlled and residual risks $[12 ; 31]$.

The literature outlines two methods for this stage namely qualitative approach such as Analytical Hierarchy Process (AHP) [32; 33] and risk matrix, and quantitative approach such as Fuzzy Logic, Failure Mode and Effect Analysis (FMEA) Tree, and Event Tree Analysis (ETA). The qualitative analysis phase focused on "the correct estimation of project's risk probability and scale accompanied effects" by using number tools while the quantitative analysis "presents tangible benefits" of what has been analyzed [34;13]. According to Berg [12], qualitative or semi-quantitative techniques such as risk graph, hazard matrices, risk matrices (most common) and monograph are usually used for screening lower risks, whereas, quantitative techniques are used for screening higher risks. In order to assess the significant of the different categories of risks identified in the literature, the participant were asked to rate them into high, medium and low on the risk scale. Table 1 below shows the result of the survey for this study.

Table 1. Risk Scale for Assessing Renewable Energy Risks

\begin{tabular}{|l|c|c|c|}
\hline \multicolumn{1}{|c|}{ Risk category } & Low & Medium & High \\
\hline Political/Regulatory risk & $28.30 \%$ & $28.30 \%$ & $43.40 \%$ \\
\hline Financial risk & $11.32 \%$ & $50.94 \%$ & $37.74 \%$ \\
\hline Technology risk & $47.17 \%$ & $35.85 \%$ & $16.98 \%$ \\
\hline Operational risk & $42.59 \%$ & $38.89 \%$ & $18.52 \%$ \\
\hline Environmental risk & $64.15 \%$ & $13.21 \%$ & $22.64 \%$ \\
\hline Construction risk & $42.59 \%$ & $38.89 \%$ & $18.52 \%$ \\
\hline Weather related risk & $20.75 \%$ & $54.72 \%$ & $24.53 \%$ \\
\hline Social risk & $72.55 \%$ & $17.65 \%$ & $9.80 \%$ \\
\hline Other risks & $67.44 \%$ & $23.26 \%$ & $9.30 \%$ \\
\hline
\end{tabular}

Nearly half of the respondents (43\%) agreed that political and regulatory risk have high impact on their projects. This result is consistent with previous research findings such as $[35 ; 18 ; 36 ; 37]$. For instance, Skytte et al. [36] uses qualitative survey to quantify the challenges that arise from change in political support systems and risk 
with respect to investment renewable energy technologies. The authors found that "political risk factors are the most" important and "difficult ones to include in the investment considerations". That is, very often risk planners "do not include (political risk factors) when calculating a risk premium". Cleijne and Ruijgrok [50] aimed to develop a model to describe and quantify the dynamics of renewable energy implementation in Europe focusing on risk as perceived by the stakeholders. The responses to their empirical data also suggest that regulatory/political risk on tariffs/financial support have high impact and are regarded to as important factors that are difficult to predict. In the same vein, Komendantova et al. [37] found that stakeholders in renewables in North Africa consider policy and regulatory risks as critical risk. Moreover, in corroboration with the finding of this study, James Green head of renewable energy practice at JLT Specialty in 2011 observed, "In the UK I was looking at 40 or so 5 -mw ground-mounted solar installations, which we were asked to insure. And overnight when the UK government said that it was going to cut the feed-in tariff, the 40 installations literally went down to four" [18].

The majority of those who responded to this survey felt that financial and weather related risk have medium impact on their projects. Although, these results are consistent with some studies, for instance [18], they differ from those conducted by Apak et al. [49] and the IEA [21]. These studies found that financial risks have high impact on renewable energy plants return on equity and on debt leverage capability and is usually included in probabilistic Discounted Cash Flow (DFC). Moreover, when the participants were asked to rate the impact of technological, operational, environmental, construction and social risks, majority of the respondents indicated that these risk factors have medium impact on their energy projects. However, when the respondents were asked the same question in relation to bio-energy projects specifically, the first risk category to emerge was financial risks with $20.79 \%$ of the respondents indicating that financial related risks have high impact on bio-energy projects. This finding is supported by $\mathrm{Xu}$ et al. [39], who writes that "payment of waste disposal fees and electricity fees require the support and cooperation of the government". The second category of risk to emerge was environmental risks as shown in Figure 4 below. 


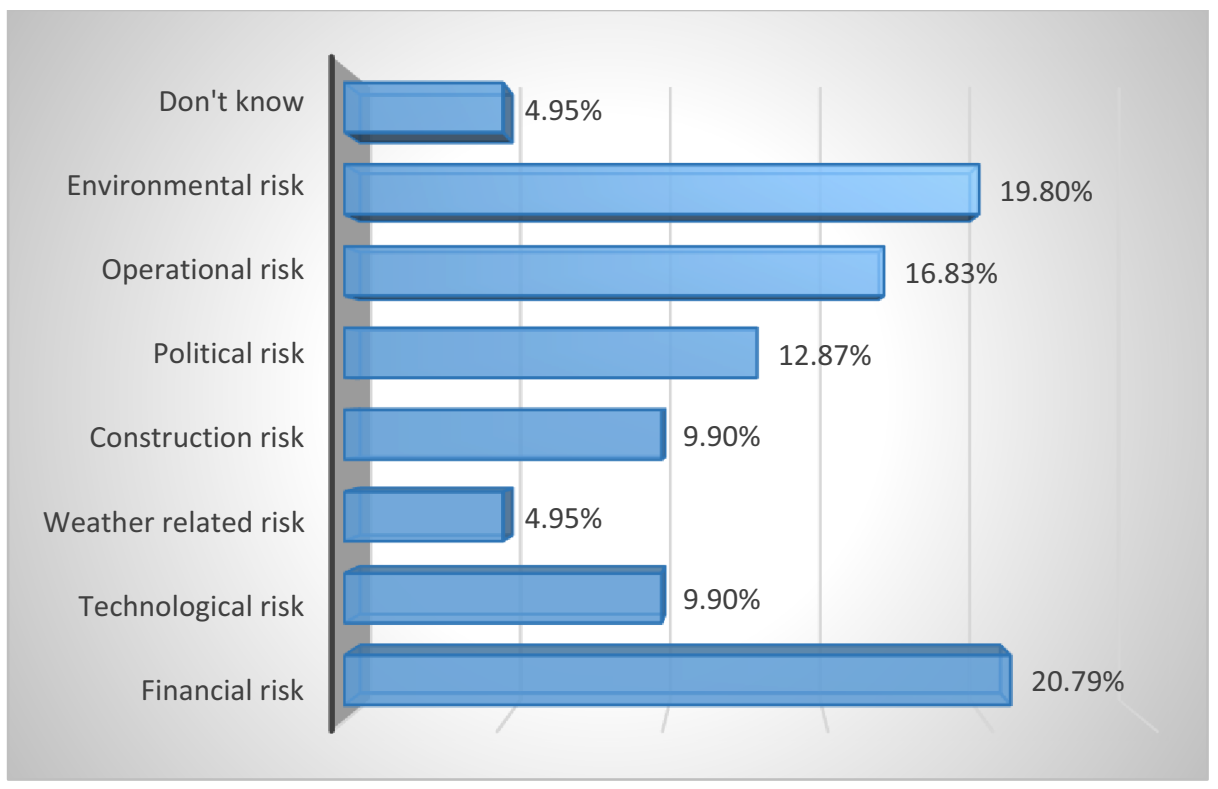

Figure 4. Risk assessment of Bioenergy Projects.

However, the findings of the current study do not support the previous research into the risks affecting the biofuel industry by Pries et al. [7]. The authors found that risk related to management and management process as well as profitability and market conditions were the most important risk affecting the biofuel industry.

\subsubsection{Risk Response: Reduction \& Mitigation}

While some authors have mainly been interested in questions concerning risk identification and assessment $[38 ; 39 ; 40 ; 41]$, Other are more concerned with risks response strategy and implemention such as risk acceptance [42], risk reduction [43], risk transfer et cetra. According to the Project Management Institute's PMBOK [15], risk mitigation is the effort of minimizing the likelihood, and/or consequences of an already identified risk in the project, prior to the occurrence of the risk event. According to a definition provided by the IEA [21], risk mitigation is "the risk handling strategy used for minimizing the probability of occurrence, negative impact of identified risk, increasing the benefits from positive risk (opportunity). These are actions taken to reduce the likelihood of an uncertain event as well as overcome the effects of risk. Risk mitigation principle may be presented at each phase of the project, from the initiation and planning stages to the closing a project stage [13]. Hitzeroth and Megerle [42] points out that attitude parameters adopted by renewable energy project stakeholders "which especially at the outset of such planning processes seemingly tend towards "acceptance" such as "incertitude" or "conditional acceptance" represent above-average pronounced risk factors in view of the project proponent's planning and cost certainty". Since project implementation (including bio-energy projects), depends on the effectiveness of the risk response mechanism adopted by both public and private stakeholders [39], it important to investigate the 
different types of response mechanisms used by practitioners in the renewable energy sector. Therefore, the participants were asked to select which risk response mechanism do they used to manage the various categories of risks.

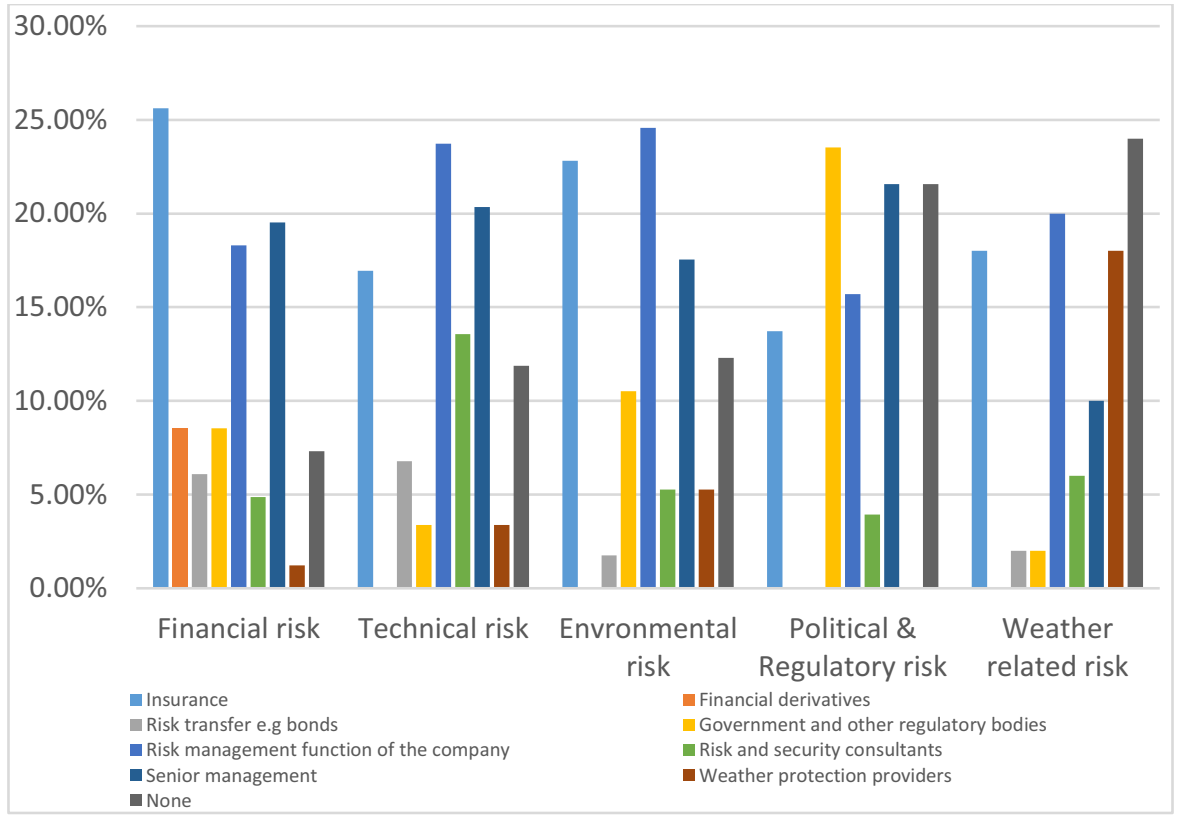

Figure 5. Risk Response Mechanisms for Different Risk Categories in Renewable Energy Projects

The majority of those who responded to the survey indicate that insurance, internal risk management function, government and other regulatory bodies, and none (that is no risk response) are the most common risk response mechanisms used to manage/response to financial, technical and environmental, political, and weather related risks respectively. Of the 60 practitioners who completed the questionnaire, $24 \%$ indicated that they do not have any risk response mechanisms for managing weather related risks. Only a small number of the respondent indicated that financial derivatives (such as bonds, market indexes and stocks) were used to manage financial risks. Overall, these results provide important insight into significant of buying insurance to manage risks in the energy sector. As the head of the insurance service group of the international finance corporation, Jan Mumenthaler put it: renewable energy developers should stop seeking to manage risks through risk transfer means, but should buy insurance to deal with it (risks). Xu et al. [39] also came to a similar conclusion about financial and environmental risk response in their study on the "critical risk factors affecting the implementation of PPP waste-to-energy projects in china" were they suggested that such risks are "better handled by the private entity" such as insurance company. Moreover, Gatzert and Kosub's [35] comprehensive study on current risks and risk management solutions of renewable energy projects 
shows that, insurance and diversification are the most important risk management tools used in renewable energy projects.

\section{Conclusions}

As renewable energy projects becomes more complex, so does the risks. The present study is designed to determine the effect of risks and risk management for bioenergy projects. According to the literature, increasing amount of companies in the energy sector are including renewable energy in their business strategies. The researchers identified five risks categories from the literature related to renewable energy projects, namely; technical risks, political and regulatory risks, financial risks, social risks, and environmental risks. According to the data collected in the questionnaire surveys, the most important risks are related to finance, policy and regulations, and the environment, which are intensified by the gloomy behaviour of the economy in many countries. Bioenergy companies consider weather related risks as less significant, despite been very important to other renewables such as wind and solar. Insurance is the main form of risk response mechanism used by companies in the bioenergy sector. Therefore, it is important to develop new financial coverages that may allow further growth in bioenergy's project financing. Moreover, political and regulatory risks were found to be managed mostly by government and other regulatory bodies external to the industry. Thus, political and regulatory risks will remain relevant to investors until policy makers begin to address these risks by integrating bioenergy industry stakeholder's perspective into their policy development process.

\section{Acknowledgments}

The authors wish to acknowledge the petroleum technology development funds (PTDF), for their immense support and sponsorship for the study as well as the School of Engineering, and the Built Environment, Faculty of Computing, Engineering and the Built Environment, Birmingham City University, United Kingdom for their assistance.

\section{References}

1. UNEP, 2016. Global Trends in Renewable Energy Investment, Frankfurt : Frankfurt School of Finance \& Managemen.

2. Langholtz, M. et al., 2014. Climate risk management for the US cellulosic biofuels supply chain. Climate Risk Management, Volume 3, pp. 96-115.

3. Adler, P. R., Grosso, S. J. D. \& Parton, W. J., 2007. Life-cycle assessment of net greenhouse-gas flux for bioenergy cropping systems. Ecological Application, Volume 17, pp. 675-691.

4. Schneider, U. A. \& McCarl, B. A., 2003. Economic Potential of Biomass Based Fuels for Greenhouse Gas Emission Mitigation. Environmental and Resource Economics, 24(4), p. 291-312.

5. Wihersaari, M., 2005. Aspects on bioenergy as a technical measure to reduce energy related greenhouse gas emissions. Konetekniikan osasto: VTT Technical Research Centre of Finland. 
6. $\mathrm{Wu}, \mathrm{Y}$. et al., 2018. A risk assessment framework of PPP waste-to-energy incineration projects in China under 2-dimension linguistic environment. Journal of Cleaner Production, Volume 183, pp. 602-617.

7. Pries, F., Talebi, A., Schillo, R. S. \& Lemay, M. A., 2016. Risks affecting the biofuels industry: A US and Canadian company perspective. Energy Policy, Volume 97, pp. 93-101.

8. Leung, W., 2001. How to Design a Questionnaire, s.1.: STUDENT BMJ .

9. Goswami, D. Y. \& Kreith, F., 2007. Handbook of Energy Efficiency and Renewable Energy. 1st ed. Boca Raton: CRC Press.

10. IRM, A., 2002. Risk Management Standard., London: The Institute of Risk Management.

11. ISO, I., 2009. 31000: 2009 Risk Management—Principles and Guidelines, Geneva, Switzerland: nternational Organization for Standardization.

12. Berg, H. P., 2010. Risk Management: Procedures, Methods and Experiences. Reliability: Theory \& Applications, 2(17).

13. Szymański, P., 2017. Risk management in construction projects. Poznań, ELSEVIER Procedia Engineering, pp. 174-182.

14. Curtis, P., Carey, M. \& Deloitte \& Touche LLP, 2012. Risk Assessment in Practice, Durham: COSO: Commitee of Sponsoring Organizations of the Treadway Commission .

15. PMI, 2013. A guide to the Project Management Body of Knowledge (PMBOK Guides). 5th ed. Pennsylvania: Project Management Institute.

16. PRINCE2, 2017. Managing successful projects with PRINCE2. 6th ed. Norwich: The Stationery Office (TSO).

17. Forbes, D. R., Smith, S. D. \& Horner, R. M. W., 2008. A comparison of techniques for identifying risks in sustainability assessment of housing. s.1., In Procs 24th Annual ARCOM Conference, pp. 1-3.

18. The Economist Group, 2011. Managing the Risk in Renewable Energy, s.1.: The Economist Intelligence Unit.

19. Balackova, H., 2002. Brainstorming: A Creative Problem-Solving Method, Prague: Masaryk Institute of Advanced Studies, Czech Technical University .

20. Hsu, C. C. \& Sandford, B. A., 2007. The Delphi technique: making sense of consensus. Practical assessment, research \& evaluation, 12(10), pp. 1-8.

21. IEA, 2011. Risk Quantification and Risk Management in Renewable Energy Projects, s.1.: Altran GmbH \& Co., KG, IEA-RETD .

22. Cuhls, K., 2002. Delphi Method, Germany: Fraunhofer Institute for Systems and Innovation Research .

23. Brahm, C. \& Kleiner, B. H., 1996. Advantages and disadvantages of group decision-making approaches. Team Performance Management. An International Journa, 2(1), pp. 30-35.

24. Wood, G. D. \& Ellis, R. C. T., 2003. Risk management practices of leading UK cost consultants. Engineering, Construction and Architectural Management, 10(4), pp. 254-62.

25. IRM, 2008. Innovation, Value Creation and Opportunity Special Interest Group, s.1.: The Institute of Risk Management .

26. Rostami, A., 2016. Tools and techniques in Risk identification: a research within SMEs in the UK construction industry. Universal journal of management, 4(4), pp. 203-210.

27. Kansal, R. K. \& Sharma, M., 2012. Risk Assessment Methods and Application in the Construction Project. nternational Journal of Modern Engineering Research (IJMER), May-June, Volume II , pp. 1081-1085.

28. Moddares, M., Kaminskiy, M. \& Krivtsov, V., 1999. Reliability Engineering and Risk Analysis: A Practical guide. New York: Marcel Dekker, Inc. 
29. Martinez, J., 2001 . Integrated Risk Management: A Concept for Risk Containment. s.1.:CRC Press LLC.

30. Merna, T. \& Al-Thani, F., 2008. Corporate Risk Management. West Sussex : John Wiley \& Sons.

31. Bowles, D. S., 2010. Dam Safety Risk Management for Hydroelectric Projects. In International Conference on Hydropower Projects in Portugal: A New Cycle, Porto, Volume 17, p. 2015.

32. Triantaphyllou, E. \& Mann, S. H., 1995. Using the Analytical hierarchy Process for Decision making in Engineering Applications: Some Challenges. International Journal of Industrial Engineering: Applications and Practice, 2(1), pp. 35-44.

33. Saaty, T. L., 2008. Decision making with the analytic hierarchy process. Int. J. Services Sciences, Volume 1, pp. 83-98 .

34. APM, 2000. Project Risk Analysis and Management, Buckinghamshare: The Association for Project Management.

35. Gatzert, N. \& Kosub, T., 2016. Risks and risk management of renewable energy projects: The case of onshore and offshore wind parks. Renewable and Sustainable Energy Reviews, Volume 60, pp. 982-998.

36. Skytte, K. et al., 2003. Challeneges for Investment in Renewable Electricity in the European Union, Petten: Alener \& ADMIRE REBUS.

37. Komendantova, N., Patt, A., Barras, L. \& Battaglini, A., 2012. Perception of Risk in Renewable Enerfy Projects:The Case of Concentrated Solar Power in North Africa. Energy policy, Volume 40, pp. 103-109.

38. Lee, C. W. \& Zhong, J., 2015. Financing and risk management of renewable energy projects with a hybrid bond. Renewable Energy, Volume 75, pp. 779-787.

39. Xu, Y. et al., 2015. Critical risk factors affecting the implementation of PPP wasteto-energy projects in China. Applied energy, Volume 158, pp. 403-411.

40. Rolik, Y., 2017. Risk Management in Implementing Wind Energy Project. Procedia Engineering, Volume 178, pp. 278-288.

41. Jinrong, H. \& Enyi, Z., 2011. Engineering risk management planning in energy performance contracting in China. Systems Engineering Procedia, Volume 1, pp. 195-205.

42. Hitzeroth, M. \& Megerle, A., 2013. Renewable energy projects: acceptance risks and their management. Renewable and Sustainable Energy Reviews, Volume 27, pp. 576-584.

43. Guerrero-Liquet, G. C. et al., 2016. Decision-making for risk management in sustainable renewable energy facilities: A case study in the Dominican republic. Sustainability, 8(5), p. 455.

44. Bratt, G., 2010. Study of Renewable Energy Project Risk Factors Influencing the Insurance Industry, Glasgow: University of Strathclyde: Engineering .

45. Osborn, A. F., 2001. Applied Imagination. 3rd ed. New York: Creative Education Foundation Press.

46. Galway, L., 2004. Quantitative Risk Analysis for Project Management: A Critical Review, s.l.: RAND Coporation .

47. Ferraris, I., de la Canal, M. D. \& Labriola, C., 2013. Risk analysis in renewable energy: assessment of the vulnerability of the environment and community. Journal of Energy and Power Engineering,, 7(8).

48. Razaque, A., Bach, C., Salama, N. \& Alotaibi, A., 2012. Fostering Project Scheduling and Controlling Risk Management. International Journal of Business and Social Science, 3(14).

49. Apak, S., Atay, E. \& Tuncer, G., 2011. Financial risk management in renewable energy sector: Comparative analysis between the European Union and Turkey. Procedia-Social and Behavioral Sciences, Volume 24, pp. 935-945.

50. Cleijne, H. \& Ruijgrok, W., 2004. MODELLING RISKS OF RENEWABLE ENERGY INVESTMENTS, Austria: European Communities. 
51. OED, 2012. Oxford English Dictionary. 7th ed. Oxford: Franklin Watts.

52. Kytle, B. \& Ruggie, J. G., 2005. Corporate Social Responsibility as Risk Management: A Model for Multinationals, Cambridge: Harvard Kennedy School.

53. Gaurav, S., Chileshe, N. \& Ma, T., 2011. Project risk analysis of solar energy project delays in India. s.1., Solar2011, the 49th AuSES Annual Conference 30th November -2nd December .

54. Lee, P., Lam, P. T. I. \& Lee, W. L., 2015. Risks in Energy Performance Contracting (EPC) projects. Energy and Buildings, Volume 92, pp. 116-127.

55. Michelez, J. et al., 2010. Risk quantification and risk management in renewable energy projects, s.l.: Altran GmbH \& Co. KG or IEA - RETD.

56. Karytsas, S. \& Choropanitis , I., 2017. Barriers against and actions towards renewable energy technologies diffusion: A Principal Component Analysis for residential ground source heat pump (GSHP) systems. Renewable and Sustainable Energy Reviews, Volume 78, pp. 252-271..

57. Papaioannou, M. G., 2006. Exchange rate risk measurement and management: Issues and approaches for firms, (No. 2006-2255): International Monetary Fund (IMF). 